\title{
Strategies of Engineering Mechanics Course During the COVID-19 Pandemic
}

\author{
Jafril Tanjung $^{1 *}$ Nidia Sari $^{1}$ \\ ${ }^{1}$ Civil Engineering Department, Andalas University, Pauh Limau Manih, Padang 25163, Indonesia \\ *Corresponding author. Email: jafriltanjung@eng.unand.ac.id
}

\begin{abstract}
A blended learning strategy in the form of a mixture of synchronous and unsynchronous lectures in engineering mechanics course is described in this paper. The asynchronous lecture has been utilizing by the Andalas University online facilities, namely i-learn. The video of the lecture contents was also provided in this course. Meanwhile, the synchronous lecture was conducted online by using the Google Meet platform. This strategy has been carried out since Padang city experiencing an increase in cases of COVID-19 infection. Therefore, all education activities at Andalas University must be conducted online. The answers to the midterm exam were also recorded in video format. Based on the survey results to the engineering mechanics students, this blended learning strategy effectively increased students' understanding of lecture materials.
\end{abstract}

Keywords: Blended learning, engineering mechanics, covid-19, online lecture

\section{INTRODUCTION}

Structural analysis is one task in a series of detail engineering processes of the building structure. The rapid development in construction building works forces the Civil Engineering graduates to perform structural analysis quickly in high accuracy. The engineering mechanic course is addressed to learn how to conduct structural analysis works.

There are many computer software available for structural analysis, says ETABS, SAP2000, and SANSPRO. These computer-software become useless without adequate knowledge about structural analysis concepts and engineering mechanics. The engineering mechanics course contents are designed to teach the students to understand the structural analysis concept oriented towards computer software use. Sufficient enough knowledge of structural analysis will be very useful later as a constructor in building construction. The experiences in computer programming for structural analysis will explore students' competencies to think systematically and logically. Understanding this mechanic engineering course may open students' insights that the computer software for structural analysis that is widely available today is only the tool for the structural analysis process; it is not structural analysis itself.

This engineering mechanics course is the climax of the series of structural analysis lectures in the Civil Engineering Department, Andalas University. The course contents emphasize applying the operational matrix in the structural analysis concept and are only limited to analyzing twodimensional framed structures. The operational matrix is intended to facilitate computer code preparation for structural analysis based on the Direct Stiffness Method. The material for constructing the framed structures are assumed as linear-elastic materials. At the end of the course, the students are expected to have the capability to apply the matrix method to analyze the framed structures.

In the aforementioned normal conditions, the lecture was presented in class using a whiteboard and laptop dan projector. The regular daily homework was addressed to students to improve their understanding of the lecture topics. If necessary, we also hold discussions in class when the lecture is in progress. In addition to the daily homework, the students have to complete their final project, i.e., analyze the building and bridge's structural responses. For this purpose, they used computer software for structural analysis. For completing the final project, lecture assistants assisted the students, especially when using computer software.

Unfortunately, the lecture implementation activities above cannot be carried out during the current Covid-19 pandemic. Since the lecture cannot be performed face-toface, the lecture activities have to be reorganized. In this paper, the blended learning strategy in the form of a mixture of synchronous and unsynchronous lectures in engineering mechanics course is presented to avoid face-to-face lecture activities. The asynchronous lecture has been utilizing by the Andalas University online facilities, namely i-learn. Meanwhile, the synchronous lecture was conducted online by using the Google Meet platform.

\section{METHODS}

Engineering Mechanics is known as a study of the applied science in Civil Engineering. The concept of engineering mechanics is required when analyzing the 
response of civil buildings. Structural analysis is the process of determining the response of a structure for a given load. The structures' responses are shown in structural deformations and internal forces that occur in structural elements or components. The structural analysis results are then used to check their design criterion. In many cases, the structural analysis results do not always directly meet the design criteria. As a result, the structural analysis must be conducted repeatedly, so it is only effective if carried out using computer software.

During the COVID-19 pandemic, the normal lecture on engineering mechanics became difficult to implement. Face-to-face learning, discussion, and elaboration of the challenges of solving mechanical engineering problems in structural analysis cannot be realized. Therefore the learning strategy must be changed.

The iLearn facilities are available at Andalas University and make it possible to conduct online learning. Unfortunately, its system is dominated by the in one direction learning, i.e., from lecturer to students. Therefore the learning outcomes become ineffective. In this paper, a blended learning strategy in the form of a mixture of synchronous and unsynchronous lectures. The asynchronous lecture has been utilizing by the Andalas University online facilities, namely i-learn. The video of the lecture contents was also provided in this course. Meanwhile, the synchronous lecture was conducted online by using the Google Meet platform.

\section{RESULTS AND DISCUSSION}

This proposed learning strategy was evaluated after the midterm exam. Questionnaires have prepared, distributed, and fulfilled by the students who have attended the engineering mechanics course. The list of questions is given in Table 1. Actually, the questions in the questionnaire were designed in three parts. The first part (Q1) wants to make sure that online lecture is more difficult than offline lecture. The results of a survey of 37 students showed that almost $70 \%$ of them experienced difficulties in undergoing online lecturing. The second part, namely Q2 to Q5, wants to compare the use of available online learning facilities. The survey results are shown in Figures 2-5. The use of the Andalas University iLearn facilities stand-alone has been not enough for students to understand the lecture contents. From Figure 3, it can be seen that more than $80 \%$ of the students have not understood the given learning contents. Since they already have lecture material available in the iLearn facilities at the Andalas University server, a meeting platform such as google meet becomes very effective. The survey results are shown in Figures 3 and 4, where students well-understand the lecture contents. Students' use of video streams has been recommended to improve their understanding of the additional lecture contents, as shown in the survey results in Figure 5. The use of this proposed strategy has proven effective in learning engineering mechanics during the COVID-19 pandemic. Unfortunately, the consumption time for applying current lecturing has relatively much compared to conventional methods. The lecturer must prepare materials in the Andalas University iLearn system, prepare learning videos, and allocate time for lectures with online meeting platforms.

\section{Table 1 List of Questions in the Questionnaire}

Q1: Comparing to offline lectures, is the online lecture more difficult?

A 1: No, it is not difficult at all

A2 No, it is not difficult

A3: Yes, difficult

A4: Yes, difficult at all

Q2: Is the lecture by using iLearn facilities Andalas University only, without video stream, understandable?

A1: No, it is not understood at all

A2: No, it is not understood

A3: Yes, it is understood

A4: Yes, it is understood at all

Q3: Is the lecture only by using an online platform such as google meet understandable?

A1: No, it is not understood at all

A2: No, it is not understood

A3: Yes, it is understood

A4: Yes, it is understood at all

Q4: Are the blended lecture by using iLearn facilities Andalas University and online platform google meet understandable?

A1: No, it is not understood at all

A2: No, it is not understood

A3: Yes, it is understood

A4: Yes, it is understood at all

Q5: Is the lecture in the form of a video stream required in this course?

A 1: No, it is not required at all

A2: No, it is not required

A3: Yes, it is required

A4: Yes, is required at all

Q6: Are the answers to the midterm exam recorded in video format increase your understanding of the lecture's contents?

A1: No, are not increase at all

A2: No, are not increase

A3: Yes, increase

A4: Yes, increase at all

Q7: In your estimation, was your midterm exam give a satisfactory result?

A1: No, was not satisfied at all

A2: No, wat not satisfied

A3: Yes, satisfy

A4: Yes, satisfy at all 

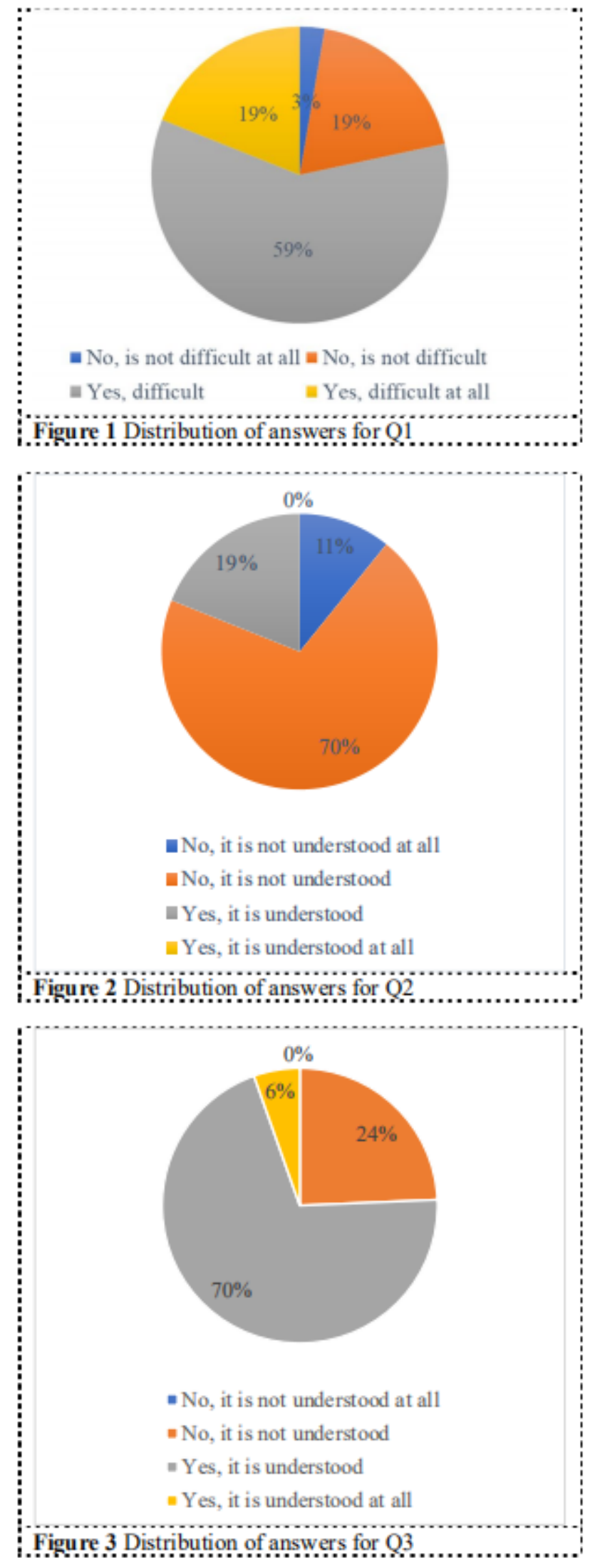

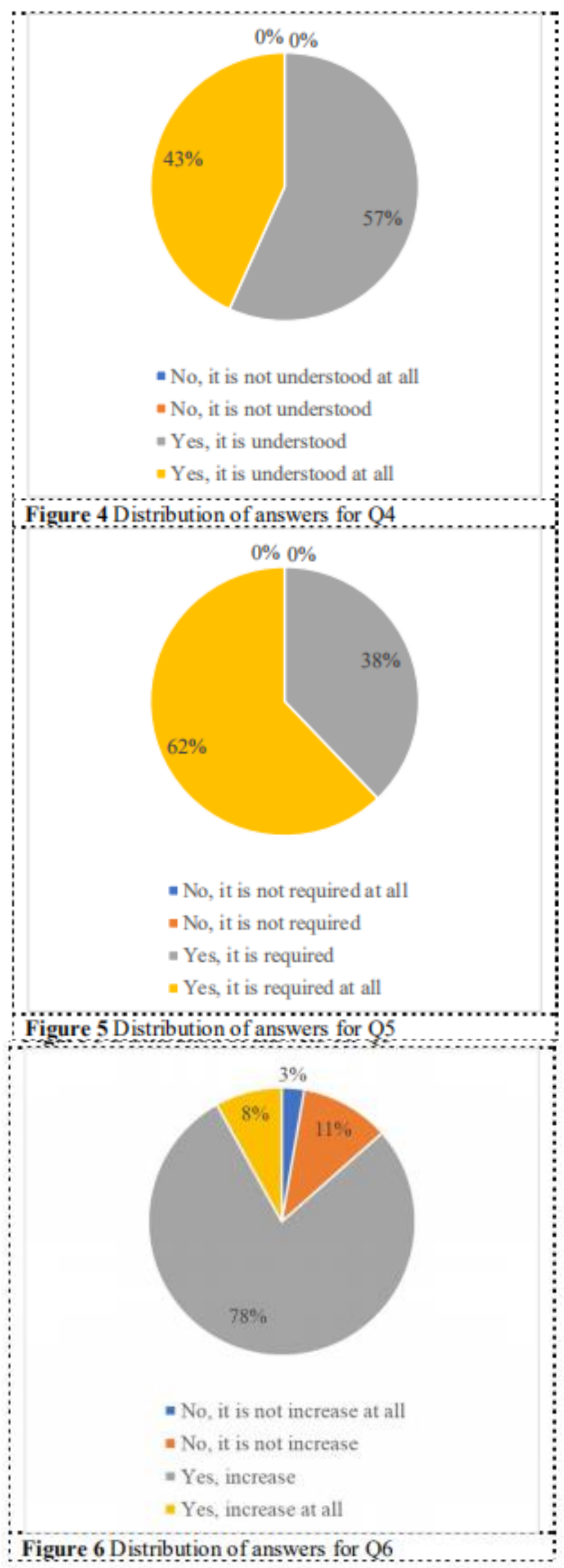




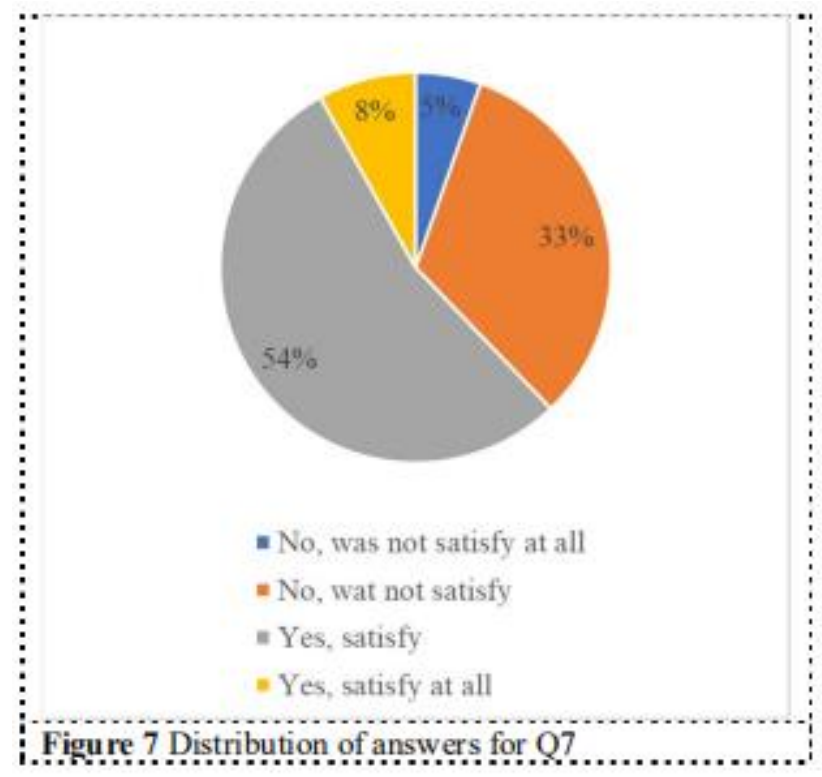

\section{CONCLUSION}

In this paper, a blended learning strategy in the form of a mixture of synchronous and unsynchronous lectures in the engineering mechanics course has been proposed. The strategy is proposed to overcome the limitation lecture method using the iLearn system provided by Andalas University. Applied the strategy for half-semester gives promising results, i.e., understanding students' level to lecture contents significantly increases.

\section{ACKNOWLEDGMENT}

The author gratefully acknowledges financial support from the LP3M of Andalas University for the grand under contract number T.016/UN.16.18/PT.01.03/2020 to publish this article.

\section{REFERENCES}

[1] B. Hariandja, Analisis Struktur Berbentuk Rangka Dalam Formulasi Matriks, Aksara Hutasada, Bandung, 1997.

[2] S.M. Holzer, Computer Analysis of Structures- Matrix Structural Analysis Structured Programming, Elsevier, New York, 1985.

[3] Y. Liu, Introduction to Finite Element Method (Lecture Notes), University of Cincinnati, 2001.

[4] D.L. Logan, A First Course in the Finite Element Method, Thomson, 2007.

[5] C.G. Page, Professional Programmer's Guide to Fortran 77, University of Leicester, 2005.

[6] J. Tanjung, Handout Analisis Struktur II, Jurusan Teknik Sipil Universitas Andalas, 2004.

[7] J. Tanjung, Penuntun Praktikum Pemograman Komputer - Bahasa Fortran, Laboratorium Komputasi
Jurusan Teknik Sipil Universitas Andalas, 2005.

[8] M.D.Vanderbilt, Matrix Structural Analysis, Quantum Publishers, New York, 1974.

[9] W.Weaver Jr dan J.M.Gere, Matrix Analysis of Framed Structures, Van Nostrand Company, 1980. 